Nephron 1973;10:65

\title{
Introduction to Calcium Symposium
}

As part of the face change of Nephron, which we hope is meeting with the approval of the nephrophils who read it, we promised to introduce symposia. This is the first of the symposia and is devoted to problems of calcium and the kidney. We decided to choose clinical scientists working in the field of renal disease, active and in the prime of their careers, and gave them a free hand to choose their own subject. We have been fortunate in the results - the articles are as varied as the personalities of their authors. We hope you appreciate that our policy has been to use well-known authors actually carrying out research in the various aspects of calcium metabolism and kidney disease, rather than people who have great names based on good work done 15-20 years ago. It is hoped that you will utilise the correspondence columns of Nephron to comment on the various articles in this symposium, as well as other nephrological topics. G. M. Berlyne Department of Nephrology, Central Negev Hospital, Beer Sheva (Israel) 